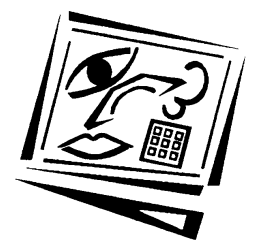

\title{
Online learning in the workplace: A hybrid model of participation in networked, professional learning
}

\author{
Mary Thorpe \\ The Open University \\ Jean Gordon \\ Jean Gordon Consultancy, UK
}

\begin{abstract}
The design and conceptualisation of online learning environments for work-related, professional learning was addressed through research with users of an online environment for social workers. The core questions for the research were to identify the nature of participation in the online environment, the relationship between online participation and the offline context, and the implications for conceptualisation of online learning environments to support work-related learning. Key areas of the research literature in technology-enhanced and work related learning are discussed in order to position the study, to inform the research methods used and interpretation of the findings. Online participation needs to be understood as a hybrid concept, in that it is a reflection of offline roles, opportunities and pressures, as well as the usefulness, usability and relevance of what is online. Online participation was diverse, from short browsing for information, to more reflective engagement that supported movement across the boundaries between roles and areas of work practice and a focus on practice skills and underlying values. Online sites intended to support work-related learning should start from the perspective of the socio-technical interaction network, with its emphasis on building in the social context at all stages in the life of a site.
\end{abstract}

\section{Online learning and learning contexts}

Web-based tools, repositories and environments are being exploited not only for professional qualifications (Waldman \& Rafferty, 2008) but also for workplace training (Newton, Hase \& Ellis, 2002, Arbaugh, Godfrey, Johnson, Pollack, Niendorf, \& Wresch, 2009), access to evidence-based practice (Gilgun, 2005) and for continuing professional development (Anderson \& Kanuka, 1997, Vrasidas \& Zembylas, 2004). The effectiveness of technology-enhanced learning in relation to the functions and constraints of workplaces is a key issue, although the diversity of such contexts presents a challenge in terms of the frameworks and issues pursued by researchers. The technology acceptance model or TAM has been developed and explored in a range of contexts and highlights key factors that have wide relevance. TAM (Davis, 1989), in its simplest form, developed out of a survey scale that produced measures on two factors, namely ease of use (defined as a perception that the technology will require little or no effort), and perceived usefulness (defined as increasing work performance). Scores on these two factors have been shown to correlate with the use/acceptance of technology, particularly in information systems (Davis, 1989). 
The core constructs of ease of use and perceived usefulness have been applied elsewhere (Roca \& Gagne, 2008), including research into e-portfolios (Shroff, Deneen \& $\mathrm{Ng}, 2011$ ), and into students' perceptions about technology in their course work by comparison with technology in work and leisure contexts (Edmunds, Thorpe \& Conole, 2012). Here, questionnaire items used in a student survey on a selection of work-related higher education courses confirmed the relevance of the two factors of usefulness and ease of use. Technology in the workplace was perceived by students to be both more useful and easier to use than technology in course study. The functional aspects of technology, what it enables the user to do and the ease with which they use it in their local context, are salient factors in both study and work contexts. Qualitative research into the same courses revealed more about the ways in which technologyenhanced learning offers valued and distinctive effects (Thorpe \& Edmunds, 2011). Technology-enhanced learning can be used to connect practitioners from different workplaces, to support disciplinary learning at employment locations, and to enable reflection on representations of work-related roles and issues included within multimedia course materials. Time constraints for work-related learning can be alleviated to some extent through the opportunity to access learning resources when travelling or between tasks. The research highlighted the importance of the concept of boundaries, between different practices and between different communities of practice. Technology-enhanced study enabled learning across the boundary between study and work, promoting stronger integration between work practices and learning.

Park and Wentling (2007) also drew on the TAM model in their research into factors specific to e-learning (text resources were provided on a CD) that are associated with the transfer of training, identifying three factors that dominate research in this area, namely interaction, learner issues, and course design issues. A correlational study of four surveys involving 47 trainee respondents based in a large manufacturing company in Midwest USA supported the importance assigned to computer attitudes and perceptions of usability in the model of factors associated with training transfer. However, Park and Wentling advised that the generalisabilty of their study was limited and further research, particularly qualitative studies, was required to gain more in-depth understanding about the influence of the organisational context, learning transfer and usability in work contexts.

The nature of work places as sites for learning has been conceptualised in terms of communities of practice, where participation in the full range of group practices ensures that novices learn what is required to become experts, capable of developing the practice themselves (Wenger, 1998). Billett also saw social participation as key, but drew attention to the diversity of individual biographies and the differential response that individuals made to the affordances of work contexts (Billett, 2004). Work-related learning is viewed as a dynamic interaction between learner identity and experience and social structures, including workplace roles, cultures and power relationships (Ecclestone, 2007). Individual orientation and capabilities directly affect perception of the workplace, and therefore choices about whether or not to engage in learning opportunities made available through structures and activities at work. Learning at work therefore is a process of co-participation between the individual or group, interacting with the opportunities available in the work environment. Billett conceived this as a 'relational interdependence between personal and social agency' (Billett, 2008), drawing attention to the different choices that individuals make, as well as to the influence of broader social structures. Learners both shape what they learn and are shaped by their work context and powerful influences within that context. 
When participation is online rather than through face to face work groups, the question of how best to conceptualise it arises. In a literature review of studies of participation in online networks for teaching and learning, Hrastinski (2008) found a range of conceptualisations of participation, but an emphasis overall on written contributions to computer-mediated forums, with some studies building this into a concept of participation as taking part in a dialogue. He noted that this ignored reading as a form of participation (see also Romiszowski \& Mason, 2004) and looked to Wenger's communities of practice model to find a 'high level conception of online participation' (Hrastinski, 2008 p.1760). He adopted Wenger's emphasis on participation as taking part in an ongoing, social relationship and argued that online participation is not measurable purely in terms of time-limited acts of writing. Hrastinski's definition, while derived purely from studies of online forums, does offer a useful reminder of the broad-based nature of participation online, which he defined as 'a complex process combining doing, communicating, thinking, feeling and belonging, which occurs both online and offline' (Hrastinski, 2008, p.1761).

Although online environments now offer more diverse forms of participation than the asynchronous forum, this form of online participation predominates in the literature. Organisations seeking to use the web to support work-related learning have typically used forums and have also been influenced by the communities of practice approach, often aiming to replicate online the claimed features of face to face practice communities. Professional development for school-based teachers had early success in building online interactive forums that drew on the strengths of local school communities (Leach, 2001). The UK National College for Leadership also introduced this approach, building online communities to support leadership development for teachers. However, participation within such online forums raises issues about how best to conceptualise the nature of this interaction, as Hrastinski argues. Thorpe, McCormick, Carmichael \& Kubiak (2007) in their study of National College for Leadership forums, suggested that offline communities played a strong role in terms of prompting online participation and the choice of issues and themes for discussion. However, few participants returned frequently to the same forum or formed an online core of practice, and the concept of a network rather than a community is more relevant to the intermittent and uneven nature of such participation online.

However, research into online learning has not always recognised the importance of the relationship between on and offline contexts. User-interface design studies may focus purely on the users' reactions to the online environment, leaving the users' context out of the picture (Cho, Cheng \& Lai, 2009). The assumption may be that a good user-interface, or an online environment designed to take contextual factors into account, could and should function freed from any further constraints arising from the physical and social context for which it has been designed. A communities of practice approach may make the same assumption, in that the online community is intended to replicate the offline community and to become the focus, even to replace the face to face.

Where research focuses on the impact or otherwise of online learning in workplaces, however, contextual factors are given weight. Reflecting on implementing online learning in the Queensland mining industry, Newton, Hase \& Ellis (2002) commented that "there were indications that the process of implementation depends on the specific idiosyncrasies of each organisation" (p.163). Vrasidas and Zembylas (2004) offer lessons learned from two professional development online projects, arguing for designs that relate directly to relevant practices in the workplace, and for active 
moderation and assessment of activity. Both studies relate to formal training or professional development initiatives that use the web, whereas online environments can be used to support the more ubiquitous informal learning that characterises engagement in social practices at work, including communities of practice. In face to face work settings, learning is frequently incidental to practice arising from activities driven by work roles and objectives. Efforts to support and enhance such learning by creating web environments in which resources can be accessed and communication engaged with, raise all the issues of design and sustainability documented above, but without the drivers of tutors or assessment to act as motivators and structuring devices.

Here the work of Kling, McKim and King (2003) offers a possible way forward in terms of their model of a socio-technical interaction network or STIN, which relates to conceptualisation of digital repositories and discussion spaces set up to serve networks of researchers or professionals. They suggest that the insights from STINs can also be extended to other electronic communication forums, including distance education electronic classrooms, professional development sites, and even community forums such as Weblogs or auction sites.' (Kling et al, 2003, p.48). The STIN is distinguished from the usual emphasis on information processing in standard approaches to escholarly communication forums, which mislead because they leave out of account factors such as the organisational and cost implications of use of information and communication technology (ICT) in particular settings, or because they assume a purely rational approach to work, 'and ignore the complexity and nuance of human motivations and relationships.' (Kling et al, 2003, p.49). Hence the implementation of online forums may prove cumbersome and time consuming in ways not predicted, or prove too costly to maintain at an effective level of contribution and currency. The STIN approach also emphasises building in the social context of users at all stages in the life of a site, not just at the beginning.

Others have also noted that the promise of technology as an obvious enhancer of knowledgeable practice and professional learning, has not delivered as anticipated (Bush \& Mott, 2009) and Trentin (2007) has specifically pointed to the need to scope not only the technology and pedagogy, but the economic, social, organisational and informal dimensions of implementation contexts. This analysis highlights the need for exploration of the relationship between work contexts and online participation. An opportunity to research this arose in relation to a project designed to support social workers in practice, through effective access to an online environment for informal learning and continuing professional development (CPD).

\section{The research context and methods}

Social work has periodically been the focus for high levels of national concern following tragic outcomes from failures of practice in the area of child protection. The Westminster Government commissioned a Task Force which reported in November 2009, specifically in relation to the situation in England, setting out recommendations for workforce improvements such as protected time for supervision and the introduction of requirements for up to 15 days of continuing professional development (CPD) in the first two years after qualification in England (Department of Children, Schools and Families, 2009). However, loss of experienced staff, together with the time pressures arising from heavy caseloads, create a challenging context for supervision and on the job learning in social work. Online learning was seen to offer the potential 
of time-efficient access to resources and expertise and the 'Practice and Professional Learning Environment' website (PePLE at http://peple.open.ac.uk/) was established in 2010 as an online environment for the CPD and supervision needs of social workers, in response initially to priorities in the Task Force report.

\section{PePLE aims and activities}

The site was designed for qualified practitioners, but social work students have periods where they have supervised time in work placements, and arrangements were made in 2011 to give access to Open University (OU) students registered on social work modules and their tutors, as an encouragement to continue learning while on placement and, once qualified, in their everyday practice. Currently the PePLE project has two main goals:

- To enable social workers to learn from practice and in practice, by using online resources and communication that expand what is immediately available to them in their workplace.

- To research how an online learning environment for professional and work-related learning is used and what factors influence usage and participation.

Two principles are embodied in design of the site, namely time-efficiency and flexibility to enable diverse usage. These principles reflected previous research showing the implications for users who are time poor and subject to workplace priorities (Thorpe, 2006; Moon, Birchall, Williams \& Vrasidas, 2005). Resources are provided in different media - text, video and audio - with structures and activities that can be used by both individuals and groups, as suits the local context. Questions and brief commentaries prompt users to reflect on resources and to relate them to their own context. Overall, ability to make good use of short periods on the site - minutes rather than hours - was a guiding principle. The site was designed and built using an open source framework. The aim was not to replicate existing repositories of research and evidence-based practice, but to offer time-efficient routes into better use of such resources, and to focus on practice, with opportunities to record learning for later use as evidence of CPD. Online participation in this context was about much more than forums, involving access and usage of a range of resources in different media. The main elements of the online environment are:

- A series of 37 short (5 minutes or less) video clips from the acclaimed OU / BBC television series, 'Someone to watch over me', which filmed social workers in action in an English city, capturing key moments from interactions with clients and colleagues. Activities provided with each clip can be used by individuals or groups to help learn from each video. Notes of responses can be made online, saved and used to provide evidence of individual learning and CPD.

- A series of reflective activities on effective supervision, using video clips to reflect on and learn from practice, prepare for and give supervision effectively. Short comments on activities give feedback to users.

- A series of knowledge for practice case studies providing activity-led guidance on finding, evaluating and making use of online resources in areas such as mental health, substance misuse, multi-agency working, learning disability, working with older people and so on. Annotated online resources are listed and linked to, so that users can access external sites from PePLE. Learning can be recorded using proformas which users can save to their own PC. 
- Online discussion forums for all users and separate forums for particular groups, e.g. practice educators.

- The 'Frameworks for Practice' section links to the learning outcome statements of the main professional bodies in the UK that regulate and set standards for qualified social workers.

- Links to the Open University and its OpenLearn site which is an extensive open educational resource at http:/ / openlearn.open.ac.uk/

The site was launched in May 2010 at a two-day event organised for Cambridgeshire social workers, who accessed the site and gave feedback on its first iteration. They were positive about the clarity of site navigability and particularly liked the ability to make notes on the videos. The site has been included within publicity on the Social Care Institute for Excellence (SCIE) and Institute for Research in Social Services (IRISS) sites and local employers have been contacted to encourage usage, particularly in Scotland. Presentations at three conferences have also promoted the site, and practitioners have registered from more than twenty county councils or local authorities in England and Scotland, from seven independent sector organisations and five universities and from elsewhere.

The literature review and our own research pointed towards the need for a qualitative study giving participants space to reflect openly and to identify issues important to them about the site, in the context of their work practices and use of ICT. Accordingly the users' perspective was explored through interviews and feedback at various stages. Social workers attended workshops and evaluated the website at the launch of the project and in January 2011. More in-depth evidence was sought through semistructured interviews, during June and July 2011. Interviewees were contacted as members of organisations and services invited to make use of the site. Participation was voluntary and interviewee comments are anonymised in the analysis. All interviews were transcribed and checked. The authors subsequently shared data coding and identified themes in the analysis (Braun \& Clarke, 2006). Quantitative data on usage of the PePLE site is also available through Google Analytics, which provides evidence of visitors to the site, frequency and extent of usage. This data offers an overview of the wider picture in terms of access to the site, and behaviour of users over the period of May 2010 to July 2011. It provides an introductory scoping of the scale of participation and a brief overview follows, leading in to the analysis of qualitative data.

\section{Quantitative data about the PePLE site}

Google Analytics defines a category called absolute unique visitors (AUVs), which is an aggregation of all visits from the same user for the active date range, regardless of how many different days they visited the site and how many times they visited on each day. Figure 1 shows the total of 2015 AUVs from May 2010 up to 29 July 2011, with 60 to 70 AUVs in each of the months prior to December 2010 when AUVs rose, reflecting opening of the site to any Open University student registered on an OU social work module, and tutors on those modules.

Visits represent the number of individual sessions initiated by all the visitors to a site. If a user is inactive on the site for 30 minutes or more, any future activity will be attributed to a new session. Users who leave the site and return within 30 minutes will be counted as part of the original session/visit. Over the period 1 May 2010 to 29 July 
2011 there was a total of 4175 visits (60 from mobile devices), averaging 9.2 visits per day; $47 \%$ of these visits were from new visitors, the rest, $53 \%$, were from returning visitors. $58 \%$ of visits lasted for less than a minute. $11 \%$ of all visits lasted from one up to three minutes, $13.5 \%$ lasted from three up to five minutes and $10 \%$ from five minutes up to thirty minutes. $7.6 \%$ (281) of all visits lasted for more than 30 minutes.

\section{Visitors Overview}

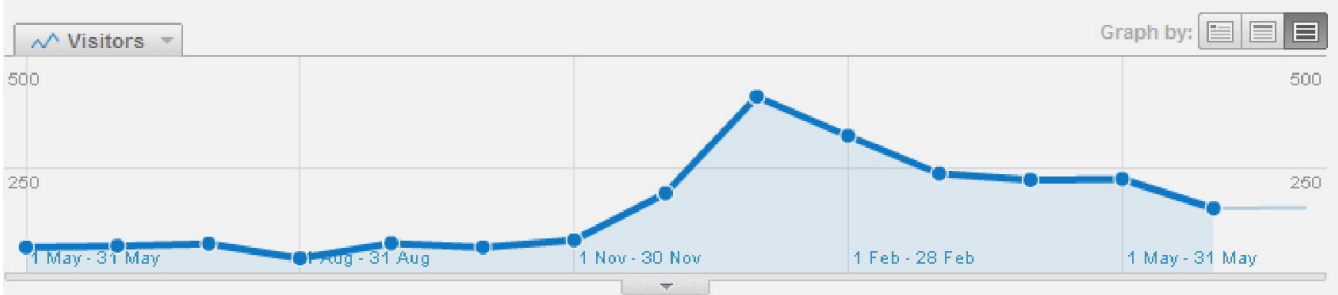

\section{2,015 people visited this site}

Figure 1: Number of absolute unique visitors (AUVs) per month, May 2010 to 29 July 2011

In terms of viewing the site, 584 pages were viewed a total of 31,941 times (see Figure 2 ), with returning visitors accounting for 23,388 page views (73\%). Average page views for all visits are 7.7, with 10.6 page views for returning visitors. Over all visits, the average time on site is 7.2 minutes per visit, with 10.4 minutes per visit for returning visitors.

\section{Top Content}

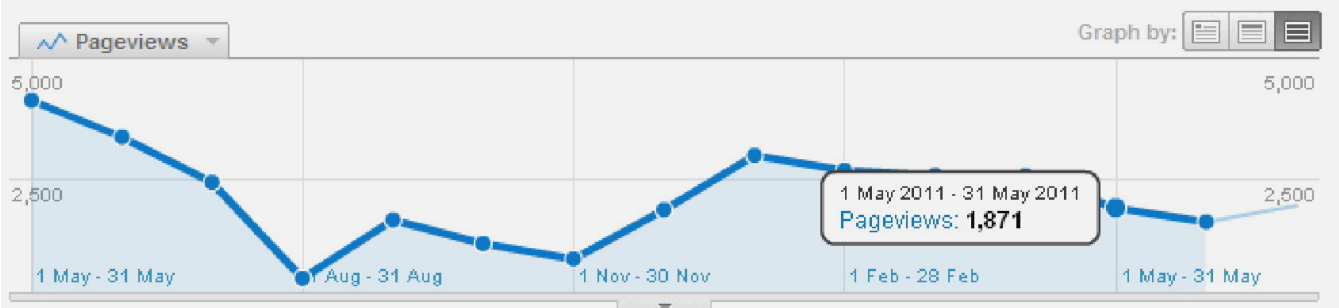

584 pages were viewed a total of 31,941 times

Figure 2: Total number of pages and page views, May 2010 to July 2011

Comparison of these data with the Google Analytics data for the OU's OpenLearn site suggests a similar picture of very brief access for a majority of users. OpenLearn, a much bigger site, has more than 5400 hours of content on its main LearnSpace. In a report on the first 18 months, over 3 million unique visitors to the site led to 75,000 $(2.5 \%)$ registrations on the site (McAndrew et al, 2009). During the first six months of 2008 , there were just over one million visitors, $82 \%$ of whom visited once only. The 
report also shows that $54.5 \%$ of all visits over April to July 2008 were 10 seconds or less and notes that these are 'bounce visitors who only visit 1 page and then leave the site' (McAndrew et al, 2009 p.37). Comparison of these data with PePLE usage shows a similar pattern to that of OpenLearn, with a high number of very short visits from users, almost half of whom were first time visitors. PePLE had a higher proportion than OpenLearn of returning visitors and visitors spending longer on the site. Eliciting qualitative data about reactions to the site focuses on those who spent some time on the site and were willing to be interviewed.

\section{Analysis of qualitative evidence from PePLE users}

The interviews were designed to elicit evidence about the fit or lack of fit, between the PePLE site and a) an individual's characteristic ways of using technology and b) their work-related practices, opportunities and constraints. Fifteen social workers were interviewed. Three were based in England and all were practice teachers (a practice teacher supports the learning of a student on placement in the workplace), one with a local authority, one with a large organisation providing legal services for court-based child protection, and one with a university involved in both on-campus degree education and support for placement students. Twelve were based in Scotland, five with social workers with a learning and development role, five from a large foster care organisation (who were interviewed as a group), one a manager in a voluntary agency, and one an independent trainer/ university social work lecturer. All interviewees participated voluntarily, having been contacted by the authors through their existing networks either as a social worker or as an employee of the Open University.

The interviews were semi-structured, using a common framework of questions about use of ICT in general as well as reactions to and use of the PePLE site. Key issues have been subsumed within a narrative focusing on a number of broad themes.

\section{Perceived ease of use and relevance of the site}

Those interviewed had few difficulties themselves in registering on the site, but felt that the registration process was a barrier to widespread usage, given that so many sites are now open and speed of access is key. Access to PePLE required contact with the project, licence signing and an invitation to register (this was changed subsequently and anyone can now register on the site and view all content, except the videos which still require signing a licence agreement). The website, however, was seen as having clear navigation and information was easy to find and not overwhelming:

Your website actually links in to other websites... but I think there's more focus to the PePLE website... folk are quite attracted by the fact it takes less time to access information through... I was selling that to the newly qualified workers because time is the main issue for all staff really... how long is it going to take me to find this piece of information, and I found your site really easy to navigate round...

I think it's very straight forward... and quite simple. It's simple to find your way about and I think that can be quite helpful if you' re busy... sometimes I only have five or ten minutes I think 'right I'll have a quick look'... if you' re quickly looking for something and... it's well laid out in that I could find stuff fairly quickly. 
All interviewees commented positively on the relevance of the site, picking up on particular areas that concerned them, such as assessing risk, or the need to use supervision effectively.

Looking at assessing risk with vulnerable people... making the right decisions and making informed decisions. ... reminding them that they're newly qualified workers and there's only so much risk that they should be involved in... But I think having those types of activities to look at, work through and discuss will help them realise... that they do have skills, they do have knowledge and experience and I think that'll boost their confidence.

I think a lot of them have no idea about supervision. ... taking responsibility for self and what you want out of supervision, preparation and planning, it's really helpful to have that in a separate place, other than your practice educator telling you.

Relevance was often seen in terms of the topics and situations covered, such as clients with mental health problems, or children judged at risk through neglect. The textbased case studies in the knowledge for practice section were also highlighted as covering relevant topics and information literacy skills which are key for CPD.

However the site was also seen as relevant because it raised issues to do with the underlying principles and values of social work practice, partly because of the questions prompting reflection by users of both the video and textual resources. The videos in particular demonstrate practice in action and therefore encourage learning about core practice issues such as communication, safeguarding, working with vulnerable people, and so on.

Two interviewees had asked their placement students to use particular videos as part of their learning on placement, and explored the results in interview. One practice teacher had used video with a student who had difficulties finding an effective way to communicate in tense and difficult situations. The student had had a difficult interview with two service users, which had not gone well. He then watched one of the video clips of a comparable situation, where the social worker has to make an agreement with parents in advance of the birth of their baby. One parent has had problems with alcohol, the other with mental health and the video shows the actual interview where the social worker asks both parents to sign an agreement about how care for the new baby will be managed.

So it was... an opportunity to look at a situation where... people would have felt that somebody was listening to them and the body language and everything was really... service-user focused So... I explained all of it to [the placement student] after the observation but then... to... take that one stage further, it was about looking... it gave a message about how you might deal with something in a different way and you get a better response from the service users.... Albeit that... the two scenarios were quite different, it was still about engaging people who were feeling quite vulnerable, and needed to be listened to. So [the placement student] was able to make the connection and see.

The practice teacher went on to emphasise the particular strength of video in this context:

I just think it brings a discussion to life really... a point where you can actually observe. It's very powerful observing people's body language and how they communicate. You could... guide somebody in terms of how they ought to approach a situation or try and 
bring about a sense of calm, or whatever, but actually seeing it live on a video I think has much more meaning.

The other practice teacher had a student who used the videos to help prepare for a placement in mental health, an area with which they were not familiar. This had enabled the student to reflect on the social work practice evidenced in the video and to identify aspects that were both positive and negative. The value of video was seen as bringing practice to the fore in ways that do not generally happen in the pressure of day to day work focused on managing case loads:

It's very difficult I think to try and ensure that we look at what is good practice. Every social worker in the code of practice has got to ensure that they are looking at their own core values and their practice. How many of us actually do that I wonder?

She also reflected on the way that the videos enabled the student to anticipate how it might feel to work in different areas of practice - an important preparatory device for anybody moving into an unfamiliar practice context, not only for the student. She also recognised that the videos require some sophistication on the part of the user, given that each social worker will not see the particularities of their own cases or working context revealed there. The user needs to make connections themselves through seeing points of similarity or issues common across different areas of practice:

The [video clips] are good if you can adapt them and you can take away the fact of what service user you are looking at and focus on practice, on social work practice, on social work core values. Was there an element of dignity and respect given to the service user? ... Was the person acting as an advocate and encouraging the person to be independent? All those things you could use.

\title{
Workplace practices, ICT and the PePLE site
}

All interviewees did use ICT regularly and described moving across a range of sites, usually for quick access to information rather than something seen as 'learning', as in this comment:

\begin{abstract}
... have my Netbook with me here which has got all my bookmarks open here... I use websites for policy quite a lot... I've got training games... mind tools... I click about very quickly, being a part-timer with different jobs... I don't have lots of time... so if I can't find something very quickly I tend to be off and on somewhere else.
\end{abstract}

This interviewee also described herself graphically and how she used ICT; 'it's me bombing about it like a little bee at a hundred miles an hours!'. She demonstrated how quickly impressions online are formed - mention of the General Social Care Council first led her to assume the resource was only for England, even though Scottish organisations and references were included elsewhere. Users do not read closely through a site, but take glimpses from which impressions are formed, correctly or otherwise.

Usage of the PePLE site was related to key stages in the social work career, with the immediate two to three years after qualifying seen as more promising than later stages. One interviewee provided a cameo of the way use of the site could support her role with newly qualified social workers:

So for me... there's a structure and being able to go back to the group and saying like 'OK you've asked for this, how does this sound?' and tapping into the PePLE site. So I 
see myself using it on a regular basis, dipping in and dipping out myself to help me structure and plan sessions with them but also encouraging them to dip in dip out... I think the supervision tools are really helpful as well... for me it's being able to give them pointers based on the information you've pulled together... means that I don't have to do lots of searching, lots of material finding. It's kind of all on the site already.

One interviewee commented on the section which provides an annotated list of useful online resources under key areas of practice, most of which have links directly to external sites and emphasised the realities of 'working knowledge' - the need to pull together information and experience to suit a current case or challenge.

... it is really good because having that kind of link... 'I've got half an hour... my student is learning about... bipolar, what can I quickly find out?'... students will mention stuff and I think 'oh right I've got to quickly find out about that before next week' and I'll use the Internet rather than the library... because you're not looking for an in-depth knowledge, you're looking for a working knowledge.

Some of those interviewed were social workers of considerable experience, often in roles as trainers or practice teachers, and they had all found the site useful in that role, including for the encouragement to record learning and develop good habits of learning 'on the job'.

... I've also... got new responsibilities for working with qualified social workers that I think a lot of the materials are going to be really helpful for them as well... I think the opportunities to record your learning and have somewhere to store that information on PePLE is really valuable... to have somewhere to keep it and somewhere they can dip in and dip out of it... get into the way of it so hopefully they'll then maintain that approach to their learning as their professional development progresses...

The site was seen as different from other online sites for social workers, because PePLE focuses on learning in and from practice rather than information per se, and could act as an important reminder for the experienced as well as the newly qualified.

And I think... the bit about supervision on the PePLE site is really quite helpful in the early stages of being in that role but also I think it's quite useful to serve as a reminder. Because when I've gone back to it... it has reminded me of the purpose of supervision and that it's more than simply... talking about somebody's case work. ... because you lose sight given the stress of the day to day work of what your role is...

The physical conditions in workplaces however could make accessing the site difficult - shared offices, needing to use headphones to watch videos, and so on, but cultural expectations also create barriers.

... there's a perception I think from staff that if you're in work and you're in the office and you've got headphones you're watching something happening on the screen, that you might not actually be doing work. Which is obviously not the case.

Another commented on the way the site could support individual learning where a workplace is not supportive of learning, helping in the transition from student to qualified social worker:

... let's face it not everybody goes out to a supervisor that is... particularly helpful or useful and I always encourage students to try to contemplate the possibility that they will get a useless senior, and therefore they're going to have to self-supervise to some extent, and how would they do that. And I thought a lot of the material and the fact 
that they could record things on their learning log for themselves, would help them to build those skills in terms of their own abilities.

\section{Discussion}

The qualitative evidence base used in the research was restricted in terms of the number of interviewees, reflecting constraints on accessing work-based users for research purposes. Our findings are indicative rather than exhaustive, and point towards the need for more research to illuminate the relationships between a wider range of work-related contexts and online participation. However we do note similarities between existing research and a number of our findings. The qualitative findings suggest that online sites intended to support work-related learning should start from the perspective of the socio-technical interaction network or STIN, with its emphasis on building in the social context at all stages in the life of a site. Understanding of the object of the practitioners at whom the site is directed needs to be embodied not only in the content of the site, but in the ways that users can appropriate what is there and make it part of their own practice.

Both usefulness and ease of use remain strategically important factors in online participation. Ease of use, interpreted here as easy access, clear navigation and visible structure, still remained a necessary condition for usage, with users unlikely to persist if something interesting and relevant was not found quickly. However as important as these technical factors, is the actual content of the site. Relevance to a local practice has been key to the response of interviewees and their likely continued usage of the site. Regular users of ICT commented on the way in which their online practice involves short forays into sites and resources - 'dip in dip out' is a good characterisation of the approach. They expect to find something useable within a very short time frame, with an attention span of a few minutes being typical.

The evidence from the quantitative data about site usage suggests that this is typical of most users, not just the interview group. Over two thousand people visited the site since its launch to the end of July 2011, making over 4000 visits of which just over half were from returning visitors who spent on average ten minutes per visit making just over 10 page views. The nature of this usage therefore can be characterised as extremely time limited and eclectic. Evidence that this is a widespread approach to use of the web comes from a study of scholars' use of e-journal databases, collections and research gateways over five years, undertaken by the CIBER group at University College London (UCL, 2008). They reported as follows:

The main characteristics of digital information seeking behaviours in virtual libraries are:

Horizontal information seeking - a form of skimming activity, where people view just one or two pages from an academic site and then 'bounce' out, perhaps never to return. ... Around $60 \%$ of e-journal users view no more than three pages and a majority (up to $65 \%$ ) never return.

Navigation - People in virtual libraries spend a lot of time simply finding their way around... they spend as much time finding their bearings as actually viewing what they find.

Viewers - the average times that users spend on e-book and e-journal sites are very short: typically four and eight minutes respectively. ... there are signs that new forms of 'reading' are emerging as users 'power browse' horizontally through titles, contents 
pages and abstracts going for quick wins. It almost seems that they go online to avoid reading in the traditional sense. (UCL, 2008, p.10)

This overview thus enables us to put our evidence into context, demonstrating that online provision has to work within an expectation that site usage will often be a matter of minutes only. The mode of usage described above presents a very different picture from the way participation is defined in studies of workplace learning, focusing as it does on learning in the face to face workplace as an integral part of work activity, with long term learning trajectories. However the potential for diverse forms of participation online was evident. The 'dip in dip out' forms of browsing and capture of relevant information dominated usage, but the potential for more reflective engagement was also recorded. The videos were used in diverse ways: for the novice, preparation for moving into a new area of practice, or for developing improved communication skills; for the experienced social worker, as a reminder of core values and the importance of a practice focus when case loads dominate work time. However even the inclusion of reflective questions on the site within text resources were valued as prompts for thinking about one's practice and how it might be developed. A distinction was made between information and the way in which the site focuses the user on social work practice. This in itself was seen as valuable.

Users require skills in making connections between the site and their face to face communities in ways that enable them to learn in practice. Participation, in other words, has both an offline and an online component. The user sees examples of practice, or text-based scenarios of practice, which require an act of imagination on their part, in order to see the connection between that and their local practice. Encouraging others to use the site also involved a rhetorical act of persuasion - 'look at this instance of practice online - it's not your practice but it's relevant because... [or] there is useful information here that can help you because... or 'look here for a stimulus to reflect on your practice or develop it further'. Although many of our interviewees had roles as learning facilitators, they were still close to practice, being based within social work providers and they demonstrate the importance of both being 'in practice' but also having imagination to see where the points of connection are between one's own practice and a generic online resource.

\section{Conclusion}

Informal learning online in the workplace which is not assessed or mandated by training requirements, has to be accessed voluntarily by the user. Previous research, though often focusing on formal online training or organised learning projects, has emphasised the importance of the local organisational context as a factor in effective implementation and usage. Research into usage of an online site for the support of informal practitioner learning within social work has provided evidence of the ways in which the offline context stimulates online participation, through processes such as meeting role demands, developing expertise, and being aware of relevant themes and issues, sometimes supported by encouragement and facilitation. Online participation also feeds back into practitioner reflection and has the potential to develop practice. Online participation therefore needs to be understood as a hybrid concept, in that it is a reflection of offline roles, opportunities and pressures, as well as the usefulness and usability of what is online. Hrastinski's (2008) definition of participation as a complex process that occurs both offline and online is substantiated by this research. Work in both open educational resources (Lane, 2010) and STINs also points in a similar 
direction, towards engagement with workplace users and communities throughout and not just at the beginning for purposes of design. As emphasised in the work of Kling, McKim and King:

... it becomes clear that new technological developments will not wash away the issues of sustainability and integration into a social world. (Kling, McKim \& King, 2003, p.63).

Sites have to prove robust within the extreme time pressures of the workplace, as illustrated in this research. They can also build evidence about usage as part of their content, and incorporate user perspectives as these develop. Informal online learning is conceived as working synergistically with place-based roles and communities, not as building an online space that can substitute for them. The benefits of accessing online resources and networking range from finding relevant information and contacts through to anticipating the challenges of working in an unfamiliar area or new role, to being reminded of the core values and principles of social work practice. These benefits can be realised even using short time periods for browsing, viewing or reading, in part because they are relevant to and complement what is occurring in the workplace at the time. Brief and even casual participation online is likely to be the reality for much informal workplace learning. Understanding of the practices of the practitioners for whom the site is intended, needs to be embodied not only in its content and design but also in the ways that users can appropriate what is there and make it part of their own practice.

\section{Acknowledgments}

The PePLE project was collaboratively developed by the Institute of Educational Technology and the Department of Social Work, Faculty of Health and Social Care, both of the Open University (OU). It was funded originally by one of four OU Centres of Excellence in Teaching and Learning (CETL) which were themselves awarded five years of funding by the Higher Education Funding Council for England. The PracticeBased Professional Learning CETL (http:/ / www8.open.ac.uk/opencetl/) funded the initial development of the site in 2010, and the OU Development Fund contributed resource for its development in 2010-2011.

\section{References}

Anderson, T. \& Kanuka, H. (1997). On-line forums: New platforms for professional development and group collaboration. Journal of Computer Mediated Communication, 3(3).

http:/ / jcmc.indiana.edu/vol3/issue3/anderson.html

Arbaugh, J. B., Godfrey, M. R., Johnson, J., Pollack, B. I., Niendorf, B. \& Wresch, W. (2009). Research in online and blended learning in the business disciplines: Key findings and possible future directions. The Internet and Higher Education, 12, 71-87. http: / / dx.doi.org/10.1016/j.iheduc.2009.06.006

Billett, S. (2004). Co-participation at work: Learning through work and throughout working lives. Studies in the Education of Adults, 36(2), 190-205. http: / / open.library.ingentaconnect .com/ content/ niace/ stea/2004/00000036/00000002/art00004; also at http: / / www98.griffith.edu.au/ dspace/ downloaduriredirect?itemId=5111\&bitstream=1018

Billett, S. (2008). Learning throughout working life: A relational interdependence between personal and social agency. British Journal of Educational Studies, 56(1), 39-58. http: / / dx.doi.org/10.1111/j.1467-8527.2007.00394.x 
Braun, V. \& Clarke, V. (2006). Using thematic analysis in psychology. Qualitative Research in Psychology, 3(2), 77-101. http:/ / dx.doi.org/10.1191/1478088706qp063oa

Bush, M. D. \& Mott, J. D. (2009). The transformation of learning with technology: "Learnercentricity, content and tool malleability, and network effects". Educational Technology, 49(2), 320. http:/ / eric.ed.gov/ERICWebPortal/ detail?accno=EJ829873

Cho, V., Cheng, T. C. E. \& Lai, W. M. J. (2009). The role of perceived user-interface design in continued usage intention of self-paced e-learning tools. Computers $\mathcal{E}$ Education, 53(2), 216227. http:/ / dx.doi.org/10.1016/j.compedu.2009.01.014

Davis, F. D. (1989). Perceived usefulness, perceived ease of use, and user acceptance of information technology. MIS Quarterly, 13(3), 319-340. http: / / www.jstor.org/ stable/10.2307/249008

Department of Children, Schools and Families (2009). Building a safe, confident future. The final report of the Social Work Task Force: November 2009. http: / / www2.warwick.ac.uk/ fac/soc/ shss / courses / social_work_task_force_final_report.pdf

Ecclestone, K. (2007). An identity crisis? Using concepts of 'identity', 'agency' and 'structure' in the education of adults. Studies in the Education of Adults, 39(2), 121-131. http: / / connection.ebscohost.com/c/articles / 27668743/ editorial-identity-crisis-usingconcepts-identity-agency-structure-education-adults

Edmunds, R., Thorpe, M. \& Conole, G. (2012). Student attitudes towards and use of ICT in course study, work and social activity: A technology acceptance model approach. British Journal of Educational Technology, 43(1), 71-84. http:/ / dx.doi.org/10.1111/j.14678535.2010.01142.x

Gilgun, J. F. (2005). The four cornerstones of evidence-based practice in social work. Research on Social Work Practice, 15(1), 52-61. http:/ / dx.doi.org/10.1177 / 1049731504269581

Hrastinski, S. (2008). What is online learner participation? A literature review. Computers $\mathcal{E}$ Education, 51(4), 1755-1765. http: / / dx.doi.org/10.1016/j.compedu.2008.05.005

Kling, R., McKim, G. \& King, A. (2003). A bit more to it: Scholarly communication forums as socio-technical interaction networks. Journal of American Society for Information Science and Technology, 54(1), 47-67. http:/ / dx.doi.org/10.1002/asi.10154

Lane, A. (2010). Designing for innovation around OER. Journal of Interactive Media in Education, 10(2). http: / /jime.open.ac.uk/jime/ article/view/2010-2

Leach, J. (2001). Teaching's long revolution: From ivory towers to networked communities of practice. In F. Banks \& A. Shelton Mayes (Eds.), Early professional development for teachers. London: David Fulton.

McAndrew, P., Santos, A., Lane, A., Godwin,S., Okada, A., Wilson, T., Connolly, T., Ferreira, A., Buckingham-Shum, S., Bretts, J. \& Webb, R. (2009). OpenLearn Research Report, 2006-2008. The Open University. http:/ / oro.open.ac.uk/17513/2/Research_forWeb.pdf

Moon, S., Birchall, D., Williams S. \& Vrasidas, C. (2005). Developing design principles for an elearning programme for SME managers to support accelerated learning at the workplace. The Journal of Workplace Learning, 17(5/6), 370-384. http: / / dx.doi.org/10.1108/13665620510606788

Newton, D., Hase, S. \& Ellis, A. (2002). Effective implementation of online learning: A case study of the Queensland mining industry. Journal of Workplace Learning, 14(4), 156-165. http: / / dx.doi.org/10.1108/13665620210427285 
Park, J. \& Wentling, T. (2007). Factors associated with transfer of training in workplace elearning. Journal of Workplace Learning, 19(5), 311-329. http: / / dx.doi.org/10.1108/13665620710757860

Roca, J. C. \& Gagne, M. (2008). Understanding e-learning continuance intention in the workplace: A self-determination theory perspective. Computers in Human Behavior, 24(4), 1585-1604. http: / / dx.doi.org/10.1016/j.chb.2007.06.001

Romiszowski, A. \& Mason, R. (2004). Computer mediated communication. In D. H. Jonassen (Ed.), Handbook of research for educational communications and technology. New Jersey: Lawrence Erlbaum, 397-431.

Shroff, R. H., Deneen, C. \& Ng, E. M. W. (2011). Analysis of the technology acceptance model in examining students' behavioural intention to use an e-portfolio system. Australasian Journal of Educational technology, 27(4), 600-618. http: / / www.ascilite.org.au/ajet/ ajet27/ shroff.html

Thorpe, M. (2006). Perceptions about time and learning: Researching the student experience. Distances et Savoirs, 4(4), 499-511. http: / / www.cairn.info/ revue-distances-et-savoirs-2006-4page-497.htm

Thorpe, M., McCormick, R., Carmichael, P. \& Kubiak, C. (2007). Talk in virtual contexts: Reflecting on participation and online learning models. Pedagogy, Culture and Society, 15(3), 349-366. http: / / dx.doi.org/10.1080/14681360701602265

Thorpe, M. \& Edmunds, R. (2011). Practices with technology: Learning at the boundary between study and work. Journal of Computer Assisted Learning, 27(5), 385-398. http: / / dx.doi.org/10.1111/j.1365-2729.2010.00405.x

Trentin, G. (2007). A multidimensional approach to e-learning sustainability. Educational Technology, 47(5), 36-40.

UCL (University College London) (2008). Information behaviour of the researcher of the future. London: University College London. CIBER Briefing paper, 9. [viewed 19 Oct 2011] http:// www.ucl.ac.uk/infostudies/research/ciber/downloads/ggexecutive.pdf

Vrasidas, C. \& Zembylas, M. (2004). Online professional development: Lessons from the field. Education E Training, 46(6/7), 326-334. http: / / dx.doi.org/10.1108/00400910410555231

Waldman, J. \& Rafferty, J. (2008). Technology-supported learning and teaching in social work in the UK - A critical overview of the past, present and possible futures. Social Work Education, 27(6), 581-591. http: / / dx.doi.org/10.1080/02615470802201531

Wenger, E. (1998). Communities of practice: Learning, meaning and identity. Cambridge: Cambridge University Press.

Authors: Professor Mary Thorpe, The Institute of Educational Technology,

The Open University, Walton Hall, Milton Keynes MK7 6AA, UK

Email: m.s.thorpe@open.ac.uk Web: http: / / iet.open.ac.uk/ people/m.s.thorpe

Jean Gordon, Social Work Consultant. Email: jean@jeangordon.co.uk

Please cite as: Thorpe, M. \& Gordon, J. (2012). Online learning in the workplace: A hybrid model of participation in networked, professional learning. Australasian Journal of Educational Technology, 28(8), 1267-1282.

http: / / www.ascilite.org.au/ajet/ajet28/thorpe.html 